\title{
ОЦЕНКА ВЛИЯНИЯ СТРУКТУРЫ ИНВЕСТИЦИЙ НА РОСТ ВАЛОВОГО РЕГИОНАЛЬНОГО ПРОДУКТА *
}

\author{
(c) 2021 Олейник Елена Борисовна
}

доктор экономических наук, доцент, профессор кафедры

Дальневосточный федеральный университет, Россия, Владивосток

E-mail: oleynik.eb@dvfu.ru

\section{(C) 2021 Захарова Алена Петровна}

кандидат экономических наук, доцент, доцент кафедры

Дальневосточный федеральный университет, Россия, Владивосток

E-mail: zakharova.ap@dvfu.ru

\section{(C) 2021 Юрченко Елена Григорьевна}

кандидат физико-математических наук, доцент, доцент кафедры Дальневосточный федеральный университет, Россия, Владивосток

E-mail: yurchenko.eg@dvfu.ru

В статье рассмотрено понятие качества экономических структур и предложен показатель - индекс качества структуры инвестиций. С помощью панельной регрессионной модели выявлены значимые факторы и получены количественные оценки роста ВРП на душу населения в Дальневосточном федеральном округе. Установлено, что создание дополнительных «территорий опережающего развития» незначимо влияет на рост ВРП. Разработанная модель позволят определить сценарии и сформировать комплексы действий по экономическому и социальному развитию на основе детальной региональной статистики.

Ключевые слова: экономический рост, структура валового регионального продукта, инвестиции, эконометрическая модель, качество структуры.

Инвестиции - это индикатор социальноэкономического развития территории. Их постоянный приток необходим для обеспечения дальнейшего устойчивого роста валового регионального продукта (ВРП) и валового внутреннего продукта (ВВП) в целом. Для привлечения инвестиций в разных странах (Япония, Китай, Россия, Сингапур и других) создаются особые экономические зоны - территории, в которых предоставляются разработанные в рамках государственных программ условия для привлечения иностранных инвесторов, иностранных технологий и высокопрофессиональных специалистов, действуют налоговые льготы и административные преференции. Такие территории это открытые инновационные системы, целью создания которых является формирование благоприятных условий для развития бизнеса и экономики и инструмент регионального развития, ориентированный на глобальную конку- рентоспособность и сотрудничество с зарубежными партнерами.

Выбор приоритетных инвестиционных проектов, распределение и перераспределение инвестиций по отраслям при неизменном объеме по-разному может влиять на рост ВРП. Следовательно, нужна не только количественная, но и качественная характеристика инвестиций, поступающих в экономику региона, то есть нужен показатель качества структуры инвестиций.

Критериями качества экономического роста в основном выступает снижение показателей дифференциации уровней экономического развития регионов - структурные изменения $[7,8]$ и структурные уравнения [13]. Подходы к оценке качества экономического роста с учетом динамики различных элементов структуры ВРП рассмотрены в [2]. В [4-6, 12] предложены оценки качества структуры и структурных соотношений параметров экономики, которые улучшают ка-

\footnotetext{
* Работа подготовлена в рамках гранта РФФИ № 19-010-00085 «Комплексная оценка структурной динамики экономической системы Дальневосточного региона на основе моделирования результатов стратегических инвестиционных проектов»
} 
чество структуры и обеспечивают экономический рост. Влияние особых экономических зон с налоговыми льготами на экономику региона рассмотрено в $[1,3]$ и других.

В изученных нами работах не приводится четкого определения качества структуры инвестиций, нет какого-то единого, общего определения качества структуры экономики на современном этапе. Это объясняется значительными различиями в уровне развития стран или регионов, поэтому в одних работах уделяется внимание производственной составляющей качества экономического роста, в других - социальной составляющей.

Для оценки структурных эффектов ВРП регионов часто используют модели панельных данных. Методы построения регрессий на панельных данных подробно описаны в [9-11,14] и других научных работах.

Подводя итоги анализа, можно сделать следующий вывод: так как российская экономика имеет ярко выраженную ресурсную направленность, то одним из показателей качества структуры инвестиций является преимущественное развитие обрабатывающих производств, особенно предприятий глубокой переработки ресурсов.

На основании рассмотренных подходов мы предлагаем инструментарий для оценки роста ВРП в зависимости от качества структуры инвестиций.

Методология исследования. В своей работе мы будем использовать следующие понятия:

- «структура», то есть доли и пропорции между элементами. Например, доли субъектов в ВРП или инвестиции, распределенные по видам деятельности;

- «структурные сдвиги», изменение долей и пропорций в структуре экономической системы под воздействием внешних факторов: экономических, природно-климатических, которые приводят к новому качеству системы;

- «качество структуры» - такие соотношения между элементами структуры, которые приводят к росту изучаемого показателя.

Сложность в том, что изменение каждой доли вызывает изменение соотношения и пропорций в структуре и в итоге влияет на общий темп роста исследуемого показателя. В нашей работе таким показателем, характеризующим экономический рост, является изменение объема ВРП. Постоянный приток инвестиций необходим для обе- спечения дальнейшего устойчивого роста ВРП. Для привлечения инвестиций в России созданы особые экономические зоны - «территории опережающего развития» (ТОР). ТОР - это инструмент регионального развития, ориентированный на глобальную конкурентоспособность и сотрудничество с зарубежными партнерами. Выстраивается следующий алгоритм:

- создаются особые экономические зоны (территории опережающего развития, ТОР), привлекающие инвесторов;

- инвестиции распределяются по отраслям экономики и, таким образом, формируется структура инвестиций;

- распределение инвестиций генерирует изменения (сдвиги) в структуре экономики региона;

- сдвиги в структуре экономики вызывают динамические изменения ВРП.

Сформулируем исследовательский вопрос: как качество структуры инвестиций, создание ТОР и последующие сдвиги в структуре экономики влияют на рост ВРП? Ответ на этот вопрос и является целью нашего исследования.

Мы предлагаем следующий подход к оценке качества структуры инвестиций. Структуру привлеченных инвестиций будем рассматривать в разрезе отраслей экономики, то есть через направление инвестиционных вложений определим качество структуры инвестиций. Показателем качества структуры инвестиций будет являться структурный индекс (1).

$$
I N D_{\text {quality }}=\frac{I n v_{O b r}+I n v_{Z d r}+I n v_{O b r a Z}+I n v_{I n f r}}{I n v_{D o b}}
$$

где Inv $v_{\mathrm{Obr}}$ - инвестиции в обрабатывающую промышленность; Inv $Z d r-$ инвестиции в здравоохранение; Inv $v_{\mathrm{ObraZ}}$ - инвестиции в образование; Inv Infr - инвестиции в развитие инфраструктуры; Inv $v_{D o b}-$ инвестиции в добывающую промышленность.

Чем больше единицы этот индекс, тем более качественной будет структура инвестиций. Так как экономика России имеет ресурсную направленность, то показателем качества структуры инвестиций является ее сбалансированность: превышение доли инвестиций в социальную сферу, инфраструктуру и обрабатывающие отрасли промышленности над добывающими отраслями. Такое соотношение инвестиций в перспективе должно снизить миграцию населения в 
центр из регионов.

Индикаторами качественных изменений структуры ВРП являются структурные сдвиги (формула 2) [12].

$$
S_{\text {относ }}=\sqrt{\sum_{j=1}^{n} \frac{\left(f_{j}^{l}-f_{j}^{l-1}\right)^{2}}{f_{j}^{l-1}}},
$$

где $f_{j}^{l}-$ удельный вес $j$-го элемента структуры в периоде $l ; f_{j}^{l-1}-$ удельный вес $j$-го элемента структуры в периоде $l-1 ; n-$ число элементов структуры.

В соответствии с целью исследования, были разработаны следующие гипотезы:

(H1): для регионов с экспортно-сырьевой направленностью экономики эффект от распределения инвестиций, выраженный индексом качества структуры (1), проявляется с лагом в 1 год;

(H2): на рост ВРП на душу населения положительное влияние оказывают сдвиги в структуре экономики, вызванные преимущественным распределением инвестиций в обрабатывающие отрасли промышленности, социальную сферу и инфраструктуру, а создание дополнительных ТОР незначимо влияет на рост ВРП на душу населения в регионе.
Для того, чтобы проверить выдвинутые гипотезы построим эконометрические модели.

Данные и переменные. В своем исследовании мы сделали акцент на качественных параметрах и выяснили какие переменные способствует росту ВРП на примере макрорегиона, состоящего из нескольких субъектов. Зависимой переменной в правой части уравнения будет абсолютный прирост ВРП на душу населения.

Для тестирования и проверки гипотез был выбран Дальневосточный федеральный округ (ДВФО) России. Выбор обоснован тем, что ДВФО - это крупнейший геостратегический макрорегион, который занимает более $40 \%$ территории России и является одним из самых привлекательных для инвесторов: более $32 \%$ прямых иностранных инвестиций в 2019 г. приходилось на ДВФО. Однако большая часть инвестиций направлена в добывающие отрасли, что усиливает сырьевую направленность экономики (рис. 1).

Регион богат природными ресурсами и является крупнейшим хабом для связи со странами Юго-Восточной Азии, привлекательными в качестве рынка сбыта. Данными для анализа и моделирования послужили статистические выборки за период с 2006 по 2019 год из официальных

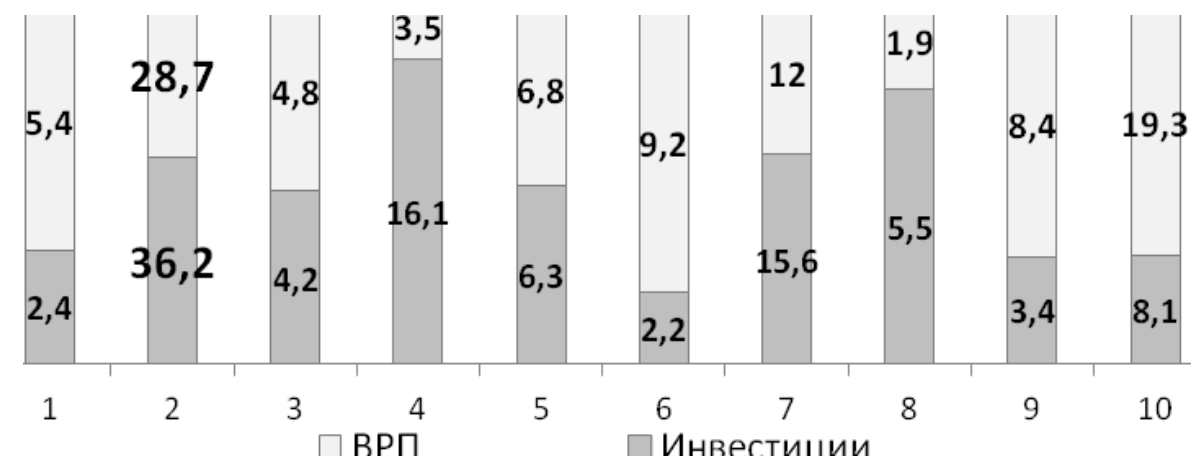

1 - Сельское, лесное хозяйство, рыболовство

2 - Добыча полезных ископаемых

3 - Обрабатывающие производства

4 - Обеспечение электрической энергией, водоснабжение

5 - Строительство
6 - Торговля оптовая и розничная

7 - транспорт и связь

8 - Инновационная деятельность

9 - Образование и здравоохранение 10 - Прочее

Puc. 1. Структура ВРП и инвестиций в основной капитал в ДВФО, \%, 2019 г. Источник: https://rosstat.gov.ru/folder/512 
источников*. Экономические параметры субъектов ДВФО изменяются с течением времени, поэтому мы будем использовать регрессии, построенные на панельных данных. Данные были преобразованы в панель из 9 кроссекций, соответствующих субъектам ДВФО, за исключением республики Бурятия и Забайкальского края. Период наблюдений 2005-2019 гг. Республика Бурятия и Забайкальский край вошли в состав ДВФО в 2018 г. и статистические данные за 2005-2017 гг. по этим субъектам несопоставимы с данными по ДВФО за этот же период. В результате исключения незначимых факторов и факторов, имеющих не интерпретируемые знаки, в регрессионную модель, построенную на панельных данных, после подгонки были включены следующие переменные: year - год наблюдения; ID - индексная переменная, которая используется для организации панели, и соответствующая субъектам ДВФО: 1 - Якутия; 2 - Камчатская область; 3 - Приморский край; 4 - Хабаровский край; 5 - Амурская область; 6 - Магаданская область; 7 - Сахалинская область; 8 - Еврейская АО; 9 - Чукотский АО.

Все остальные переменные представлены для каждого из 9 субъектов ДВФО: D_GRP дамми-переменная, принимающая значение 1 , что соответствует приросту доли субъекта в ВРП региона и 0 - иначе; Sdv_kv_GRP - квадратичные сдвиги в структуре ВРП, измеряется в долях; IND_quality - индекс качества структуры инвестиций, измеряется в долях; TAD - число действующих экономических зон с налоговыми льготами- «territories of advanced development», которые являются источником притяжения инвестиций; GRP dusha - ВРП на душу населения (рублей на человека).

С помощью такого набора переменных мы косвенно учитываем и численность населения в каждом из субъектов макрорегиона, и направления инвестиционных вложений, и, через коэффициент квадратичных структурных сдвигов, пропорциональность развития структуры. В качестве зависимой переменной используется конечная разность первого порядка переменной d_GRP_dusha, то есть ежегодный абсолютный прирост валового регионального продукта на душу населения.

Результаты. Для проверки гипотез Н1 и $\mathrm{H} 2$ были рассмотрены три типа регрессий, построенных на панельных данных модель сквозной регрессии, модель с фиксированными эффектами и модель со случайными эффектами. Все расчеты коэффициентов моделей проводились с помощью эконометрического пакета Gretle. Тест Бриша-Пэгана показал, что модель со случайными эффектами предпочтительнее сквозной регрессии $(p$-value $=0.0302772)$. А на основании теста Хаусмана можно сделать вывод, что модель со случайными эффектами предпочтительнее $(p$-value $=0.379043)$ модели с фиксированными эффектами. Результаты расчета параметров модели со случайными эффектами представлены в таблице 1.

Проинтерпретируем полученные результаты моделирования. Уравнение регрессии со случайными эффектами на панельных данных выглядит следующим образом:

$$
\begin{aligned}
& d_{V P R_{\text {dush }}}=35725.2+18453.3 * \mathbf{s} d v_{k v_{G R P}}+11046.4 * T A D+ \\
& +3.99613 * I N D_{\text {quality }_{1}}
\end{aligned}
$$

Для проверки гипотез Н1 и Н2 требуется проверить на значимость коэффициенты при переменных Sdv_kv_GRP, TAD и IND_quality в модели со случайными эффектами. Константа является значимой и положительной, следовательно, существуют и другие, достаточно влиятельные факторы, которые повышают ежегодный прирост GRP на душу населения. Однако в рамках нашего исследования мы их не рассматриваем.

В модель панельной регрессии индекс качества структуры инвестиций включен с лагом, равным одному году (IND_quality_1). Коэффициент регрессии значим по критерию Стьюдента на уровне значимости $10 \%$ ( $p$-value $=0,0974)$. Лаг объясняется тем, что эффект от распределения инвестиций проявляется не сразу, в среднем через год. Коэффициент регрессии при переменной IND_quality без лага был незначимым, и фактор был исключен из модели, таким образом

\footnotetext{
* Данные Федеральной службы государственной статистики https://rosstat.gov.ru/regional_statistics; Министерства Российской Федерации по развитию Дальнего Востока и Арктики https://minvr.gov.ru/opendata; Управления федеральной службы государственной статистики по Приморскому краю https://primstat.gks.ru/statistic; Управления федеральной службы государственной статистики по Хабаровскому краю, Магаданской области, Еврейской автономной области и Чукотскому автономному округу https://habstat.gks.ru/; данные о TOP https:/ rosinfostat.ru/territorii-operezhayushhego-razvitiya.
} 
Таблица 1. Результаты расчета параметров модели со случайными эффектами

Dependent variable: d_VPR dush

\begin{tabular}{|l|c|c|c|c|l|}
\hline & Coefficient & Std. Error & t-ratio & $p$-value & \\
\hline const & 35725.2 & 21147.9 & 1.6893 & 0.0937 & $*$ \\
\hline Sdv_kv_GRP & 18453.3 & 9327.03 & 1.9785 & 0.0501 & $*$ \\
\hline TAD & 11046.4 & 8196.06 & 1.3478 & 0.1802 & \\
\hline IND_quality_1 & 3.99613 & 2.3926 & 1.6702 & 0,0974 & $*$ \\
\hline
\end{tabular}

Breusch-Pagan test -

Null hypothesis:

Variance of the unit-specific error $=0$

Asymptotic test statistic: Chi-square $(1)=4.69348$

with $\mathrm{p}$-value $=0.0302772$

подтверждается гипотеза Н1. Следовательно, все результаты в области инвестиционной политики, связанные с ТОР, достигаются в среднем спустя год после принятия решений.

Коэффициент регрессии при переменной TAD незначим по критерию Стьюдента $(p$-value $=0.1802)$. Несмотря на то, что знак коэффициента положительный, создание дополнительных «территорий опережающего развития» в ДВФО и попытки привлечения инвесторов за счет налоговых льгот и преференций не приводят к значимому устойчивому росту ВРП.

Коэффициент регрессии при переменной Sdv_kv_GRP значим по критерию Стьюдента на уровне значимости близком к $5 \%$ (p-value=0,0501), его нужно включить в модель. Знак коэффициента положительный.

Следовательно, подтверждается гипотеза Н2 о положительном влиянии сдвигов в структуре ВРП, вызванных перераспределением инвестиций в обрабатывающие отрасли и социальную сферу. Инвестиционные проекты, связанные с таким распределением позволяют создавать предприятия с привлечением иностранных партнеров и высокой добавленной стоимостью, что и вызывает существенный рост ВРП. Создание перерабатывающих предприятий - это еще и новые рабочие места, а значит уменьшение оттока населения. А стремительное уменьшение численности населения - одна из самых серьезных проблем развития ДВФО.

Заключение. В своем исследовании мы выдвинули и подтвердили с помощью эконометрических моделей гипотезы о том, что на рост ВРП в Дальневосточном регионе положительное влияние оказывают сдвиги в структуре инвестиций, вызванные преимущественным рас-
Hausman test -

Null hypothesis: GLS estimates are consistent Asymptotic test statistic: Chi-square(3) $=3.08274$ with $\mathrm{p}$-value $=0.379043$

пределением инвестиций в обрабатывающие отрасли промышленности, инфраструктуру и социальную сферу. А «искусственное» создание дополнительных ТОР незначимо влияет на рост ВРП. Предложенный индекс качества структуры инвестиций позволяет получить оптимальные пропорции их распределения: структуру инвестиций надо сбалансировать таким образом, чтобы значение индекса было не меньше 1 , то есть совокупные инвестиции в обрабатывающие производства и социальную сферу должны быть не меньше, чем инвестиции в добывающие производства. Иначе ДВФО - стратегически важный для России макрорегион, станет только поставщиком сырья и минеральных ресурсов в страны Юго-Восточной Азии.

Включение индекса качества инвестиций в модель панельной регрессии для субъектов ДВФО позволило получить ответ на вопрос что является причиной, а что следствием: приток инвестиций или рост ВРП? Индекс включен в модель с лагом в 1 год, поэтому распределение инвестиций, для которого индекс качества превосходит единицу, является причиной роста ВРП на душу населения в будущем.

Разработанные модели позволят определить сценарии и сформировать комплексы действий по экономическому и социальному развитию на основе детальной региональной статистики. К некоторым ограничениям можно отнести тот факт, что для регионов с высокотехнологичным производством и развитой инфраструктурой и глубокой переработкой сырья индекс качества структуры инвестиций может быть сформулирован по-другому. Но это уже тема дальнейших исследований. 


\section{Библиографический список}

1. Бухвальд E.M., Валентик О.Н. Территории опережающего развития: падение или иллюзия?//Вопросы практической экономики. 2015. № 2. С.72-84.

2. Гамукин В. В. Изменение структуры ВРП в субъектах Уральского федерального округа //Экономика региона. 2017. Т. 13. вып. 2. С. 410-421.

3. Заусаев В.К. Сейчас самое главное не дискредитировать идею ТОР //Дальневосточный капитал. 2014 № 3. C. $11-12$

4. Зубаревич Н.В. Возможности и ограничения количественной оценки факторов экономического развития российских регионов// Журнал НЭА. 2020. № 2 (46). С. 158-167.

5. Исачкин В.С. Модель оценки качества отраслевой структуры экономики //Вестник Омского университета. Серия «Экономика». 2011. № 3. С. 52-56.

6. Кузнецов С.В., Якишин Ю.В. Методологический подход к оцениванию качества структуры экономики региона //Экономическое возрождение России. 2020. № 3(65). С. 12-24.

7. Масленников О.В. Качество экономического роста: сущность, факторы, показатели// Вестник ВГУ. Серия: экономика и управление. 2016. № 3 С. 5-9.

8. Михеева Н.Н. Возможные альтернативы показателю валового регионального продукта //Проблемы прогнозирования. 2020. № 1. С. 32-43

9. Arellano M., Bond S. Some Tests of Specification for Panel Data: Monte Carlo Evidence and an Application to Employment Equations // The Review of Economic Studies. 1991. Vol. 58. P. 77-97.

10. Baltagi B. Econometric analysis of panel data. 3rd Edition N. Y.: John Wiley \& Sons. 2005.

11. Breitung J., Das S. Panel Unit Root Tests under Cross-Sectional Dependence // Statistica Neerlandica.2005. Vol. 59. P.414-433.

12. Oleinik E., Zakharova A. Structural Approach to Evaluating Investments into the Region Economy // Indian Journal of Science and Technology. 2016. No 9 (12). P. 1-9.

13. Rosyadi I. Economic Structure on Gross Regional Domestic Product Growth: Study Cases in Indonesia // Russian Journal of Agricultural and Socio-Economic Sciences. 2020. Vol. 98. P. 59-66.

14. Wooldridge J.M. Econometric Analysis of Cross Section and Panel Data. Cambridge, MA: The MIT Press, 2010. 